\title{
BMJ Open Clinicopathological risk factors for gastric cancer: a retrospective cohort study in China
}

\author{
Kongwang Hu, ${ }^{1}$ Shuaili Wang, ${ }^{2}$ Zikun Wang, ${ }^{3}$ Longlong Li, ${ }^{1}$ Zhiguo Huang, ${ }^{1}$ \\ Weiqiang $\mathrm{Yu}^{2}{ }^{2}$ Zhongxue Chen, ${ }^{3}{ }^{3}$ Qing-Fa Wu ${ }^{2,4}$
}

To cite: Hu K, Wang S, Wang Z, et al. Clinicopathological risk factors for gastric cancer: a retrospective cohort study in China. BMJ Open 2019;9:e030639. doi:10.1136/ bmjopen-2019-030639

- Prepublication history for this paper is available online To view these files, please visit the journal online (http://dx.doi. org/10.1136bmjopen-2019030639).

Received 26 March 2019 Revised 28 August 2019 Accepted 02 September 2019

Check for updates

(c) Author(s) (or their employer(s)) 2019. Re-use permitted under CC BY-NC. No commercial re-use. See rights and permissions. Published by BMJ.

${ }^{1}$ Department of General Surgery, First Affiliated Hospital of Anhui Medical University, Hefei, China ${ }^{2}$ School of Life Sciences, University of Science and Technology of China, Hefei, China

${ }^{3}$ Department of Epidemiology and Biostatistics, School of Public Health, Indiana University Bloomington, Bloomington, Indiana, USA

${ }^{4}$ School of Data Science, University of Science and Technology of China, Hefei, Anhui, China

Correspondence to Professor Zhongxue Chen; zc3@indiana.edu

Professor Qing-Fa Wu; wuqf@ustc.edu.cn

\section{ABSTRACT}

Objective To examine the potential clinicopathological factors affecting the prognosis of patients with gastric cancer after surgical treatment in China.

Methods Between 1 January 2001 and 31 December 2012, a total of 716 patients aged 22-84 years with gastric cancer were enrolled in the study. Survival analysis techniques including log rank test and Cox proportional hazard regression model were applied to evaluate the prognostic significance of clinicopathological characteristics in terms of survival time.

Results of the 24 demographic and pathological variables collected in the data, 16 prognostic factors of gastric cancer were found to have statistically significant influences on survival time from the unadjusted analyses. The adjusted analysis furtherly revealed that age, age square, lymph node metastasis rate group, tumour size group, surgical type II, number of cancer nodules, invasion depth group and the interaction between surgical type II and tumour size group were important prognosis and clinicopathological factors for gastric cancer in Chinese. Conclusion Our study with relatively large sample size and many potential risk factors enable us to identify independent risk factors associated with the prognosis of gastric cancer. Findings from the current study can be used to assist clinical decision-making, and serve as a benchmark for the planning of future prognosis and therapy for patients with gastric carcinoma.

\section{INTRODUCTION}

Gastric cancer is a heterogeneous, multifactorial disease, which is known as the fifth most common cancer and the third leading cause of cancer-related death worldwide in 2018. ${ }^{2}$ According to previous reports, $\sim 0.7$ million people died because of gastric cancer each year, ${ }^{3}$ and about $70 \%$ of the gastric cancer cases had high fatality, significantly higher than other cancers such as the liver and breast cancers. ${ }^{4}$ However, the incidence and mortality of gastric carcinoma vary geographically; they were dramatically different between Western and Eastern countries. ${ }^{3}$ The highest incidence rates were found in East Asia, East Europe and part of South America, whereas the lowest rates were

\section{Strengths and limitations of this study}

This was a retrospective cohort study, including 716 participants.

- We followed up all participants for at least 5 years.

- Data of 24 independent variables were collected.

- This study has some limitations, for instance, there were missing values for some of the variables; for some subjects, the exact death time was not available and then estimated instead.

reported in North America, the UK and most parts of Africa. ${ }^{5}$ China is most notable among these countries having the highest incidence and mortality risk of gastric cancer. WHO reported that China had $\sim 456124$ new gastric cancer cases and >390128 gastric cancer deaths, with an estimated overall age-standardised incidence rate of 23.7 per 100000 in 2018. ${ }^{16}$

The epidemiological and clinicopathological characteristics of gastric cancer still largely remain uncertain, although some risk factors have been identified in the literature. It has been reported that the survival rates were lower among smokers, alcohol drinkers, obesity and people who have the symptom of esophageal acid reflux and consume pickled, salty and smoked food. ${ }^{7-9}$ Studies also suggested that the incidence rate of gastric cancer was highly correlated with age, especially among patients aged between 50 and 70 years old. ${ }^{10-13}$ It has been reported that gastric carcinoma is one of the heaviest burdens of cancer-related cost, the absolute numbers of gastric cancer cases and the prognosis remain big issues in the health programmes. ${ }^{14}$

The current most popular therapy for gastric cancer is surgery combined with chemotherapy. Surgery is the most preferred treatment for gastric carcinoma, but the survival rate of patients undergoing surgery remains very low. Previous studies have revealed that the average survival time of 
patients with advanced gastric cancer is $<12$ months ${ }^{15} 16$. Therefore, how to timely assess the condition, judge the prognosis risk after therapy and develop a reasonable postoperative care programme becomes a vital part of gastric cancer treatment. ${ }^{17-19}$

Many clinicopathological factors, including clinical stage, tumour size, infiltration depth, Lauren classification and lymph node metastasis rate, might jointly influence the prognosis in patients with gastric carcinoma. ${ }^{20-22}$ It is important but challenging to identify the most significant and independent factors associated with prognosis since many factors are highly correlated. To have a systematic comprehension of gastric carcinoma and to identify independent risk factors on gastric cancer patients, we conducted the current study.

\section{METHOD}

\section{Design}

This was a retrospective cohort study.

\section{PARTICIPANTS}

All participants were recruited from Anhui, China.

\section{Ethics statement}

The current study complied with the principles of the Declaration of Helsinki and was overseen by the human ethics committees at the First Affiliated Hospital of Anhui Medical University in China, as well as by a data and safety monitoring board (IRB approval number: PJ-2019-0219). All patients in the present study were informed and acknowledged that their medical records were potentially recorded for scientific research and that their confidentiality would be maintained.

\section{Patient and public involvement}

Patients and the public were not involved in the study design, nor the recruitment.

\section{Study cohort}

Between 1 January 2001 and 31 December 2012, 716 patients aged between 22 and 84 years with gastrectomy were registered with gastric adenocarcinoma and underwent surgery in the First Affiliated Hospital of Anhui Medical University in Anhui, China.

The WHO classification criteria and the seventh edition of the American Joint Committee on Cancer ${ }^{23}$ were used for gastric cancer macroscopic and histological classifications. Categorical and continuous clinicopathological variables were collected and analysed. Data on age (24-88), gender (male, female), Borrmann's type (I-V), Lauren's classification (intestinal type, diffuse type, others), clinical stage (0-4), T stage (I-IV, Tis), N stage (0-3), M stage $(0,1)$, tumour location (proximal, body, distal, more than two sites), surgical type I (all stomach, proximal, distal), surgical type II group (radical, palliative) and lymphovascular invasion (yes, no), were collected for each patient.
Moreover, age square was added to investigate the potential non-linear effect of age.

Other clinicopathological variables, such as positive lymph nodes number, number of retrieved lymph nodes, lymph node metastasis rate (the metastasis rate of lymph nodes), surgical margin, tumour size, number of cancer nodules, invasion depth were also collected. For those variables originally recorded as continuous were also categorised for the current analysis. Accordingly, categorical variables: number of cancer nodules group $(0,1-2$, $\geq 3$ ), positive lymph nodes number group (0, 1-6, 7-15, $\geq 16$ ), surgical margin (negative, positive), tumour size group ( $\leq 4 \mathrm{~cm}, 4-8 \mathrm{~cm}, \geq 8 \mathrm{~cm}$ ), invasion depth (mucosa, submucosa, muscular, all layer), lymph node metastasis rate group $(0, \leq 0.35,0.35-0.74, \geq 0.74)$ and number of retrieved lymph node group $(0,1-6,7-15, \geq 16)$ were also used in the analyses. However, some variables may have missing values.

The current study complied with the Strengthening the Reporting of Observational Studies in Epidemiology reporting guidelines.

\section{Statistics analyses}

In all of the analyses, the survival time defined as the period between the dates of surgery and death (or last follow-up) would be the dependent variable. All endpoints were updated between June 2018 and January 2019, which resulted in an at least 5-year follow-up for each participant. First, an unadjusted analysis was performed for each independent variable. Specifically, for each categorical (continuous) independent variable, the log rank test (the Cox proportional hazard model) was applied to see whether it is associated with the dependent variable without adjusting for any other independent variables. Then, the Cox proportional hazard regression model with backward variable selection was performed to identify factors independently assocaited with the survival time, and to estimate their adjusted HRs. In the adjusted analysis, all possible two-way interactiosn were considered in the Cox model. The 95\% CIs of the HR for significant effects were also reported. In this study, the two-sided $p$ values $<0.05$ were used to define statistical significance and all analyses were performed using SAS and SAS (r) Proprietary Software V.9.4 (TS1M2).

\section{RESULTS}

\section{Results from the unadjusted analyses}

In this cohort, the total number of events of death is 400 , and the overall median survival time is 4.74 years. The results from the univariable analyses were reported in table 1. Table 1 also listed the frequencies for each variable. This cohort was composed of 552 males and 163 females. Based on the clinical tumour, node, metastases classification, the numbers of gastric cancer patients in stage 0, I, II, III and IV were 11, 109, 296, 269 and 28, respectively. Ninety-eight patients had lymphovascular invasion while 611 did not. Gastric lesions were located 
Table 1 Results from unadjusted analyses of clinical and pathological variables $(n=716)$

\begin{tabular}{|c|c|c|c|c|c|}
\hline Variable & Frequency & Event number & $\begin{array}{l}\text { Median survival- } \\
\text { time (year) }\end{array}$ & HR & $P$ value \\
\hline Gender & & & & & 0.40 \\
\hline Female & 163 & 86 & 4.94 & 1.00 & \\
\hline Male & 552 & 314 & 4.59 & 1.10 & \\
\hline Missing & 1 & - & - & - & \\
\hline Borrmann's type & & & & & $0.030^{*}$ \\
\hline Type I & 29 & 16 & 4.40 & 1.00 & \\
\hline Type II & 514 & 288 & 4.63 & 1.06 & \\
\hline Type III & 57 & 31 & 5.06 & 1.02 & \\
\hline Type IV & 76 & 49 & 2.04 & 1.49 & \\
\hline Type V & 32 & 11 & - & 0.51 & \\
\hline Missing & 8 & - & - & - & \\
\hline Surgical margin & & & & & $0.020^{*}$ \\
\hline Negative & 648 & 353 & 4.94 & 1.00 & \\
\hline Positive & 46 & 34 & 1.55 & 1.71 & \\
\hline Missing & 22 & - & - & - & \\
\hline Lauren's classification & & & & & 0.39 \\
\hline Intestinal type & 214 & 116 & 5.67 & 1.00 & \\
\hline Diffuse type & 468 & 267 & 4.30 & 1.19 & \\
\hline Others & 32 & 16 & 8.95 & 1.03 & \\
\hline Missing & 2 & - & - & - & \\
\hline M stage & & & & & $<0.0001$ * \\
\hline 0 & 684 & 373 & 5.06 & 1.00 & \\
\hline 1 & 28 & 25 & 1.34 & 2.79 & \\
\hline Missing & 4 & - & - & - & \\
\hline $\mathrm{N}$ stage & & & & & $<0.0001^{*}$ \\
\hline 0 & 257 & 101 & 8.98 & 1.00 & \\
\hline 1 & 169 & 90 & 5.17 & 1.74 & \\
\hline 2 & 169 & 114 & 2.36 & 2.00 & \\
\hline 3 & 117 & 94 & 1.56 & 3.95 & \\
\hline Missing & 4 & - & - & - & \\
\hline T stage & & & & & $<0.0001^{*}$ \\
\hline 1 & 63 & 16 & 12.29 & 1.00 & \\
\hline 2 & 73 & 25 & 10.02 & 1.52 & \\
\hline 3 & 533 & 336 & 3.19 & 4.04 & \\
\hline 4 & 33 & 20 & 3.93 & 3.77 & \\
\hline Tis & 11 & 2 & 8.95 & 0.79 & \\
\hline Missing & 3 & - & - & - & \\
\hline Lymph node metastasis rate group & & & & & $<0.0001^{*}$ \\
\hline 0 & 257 & 101 & 8.98 & 1.00 & \\
\hline$\leq 0.35$ & 200 & 101 & 5.64 & 1.53 & \\
\hline $0.35-0.74$ & 159 & 109 & 2.11 & 2.86 & \\
\hline$\geq 0.74$ & 95 & 81 & 1.50 & 4.25 & \\
\hline Missing & 5 & - & - & - & \\
\hline Surgical type I group & & & & & 0.13 \\
\hline
\end{tabular}


Open access

Table 1 Continued

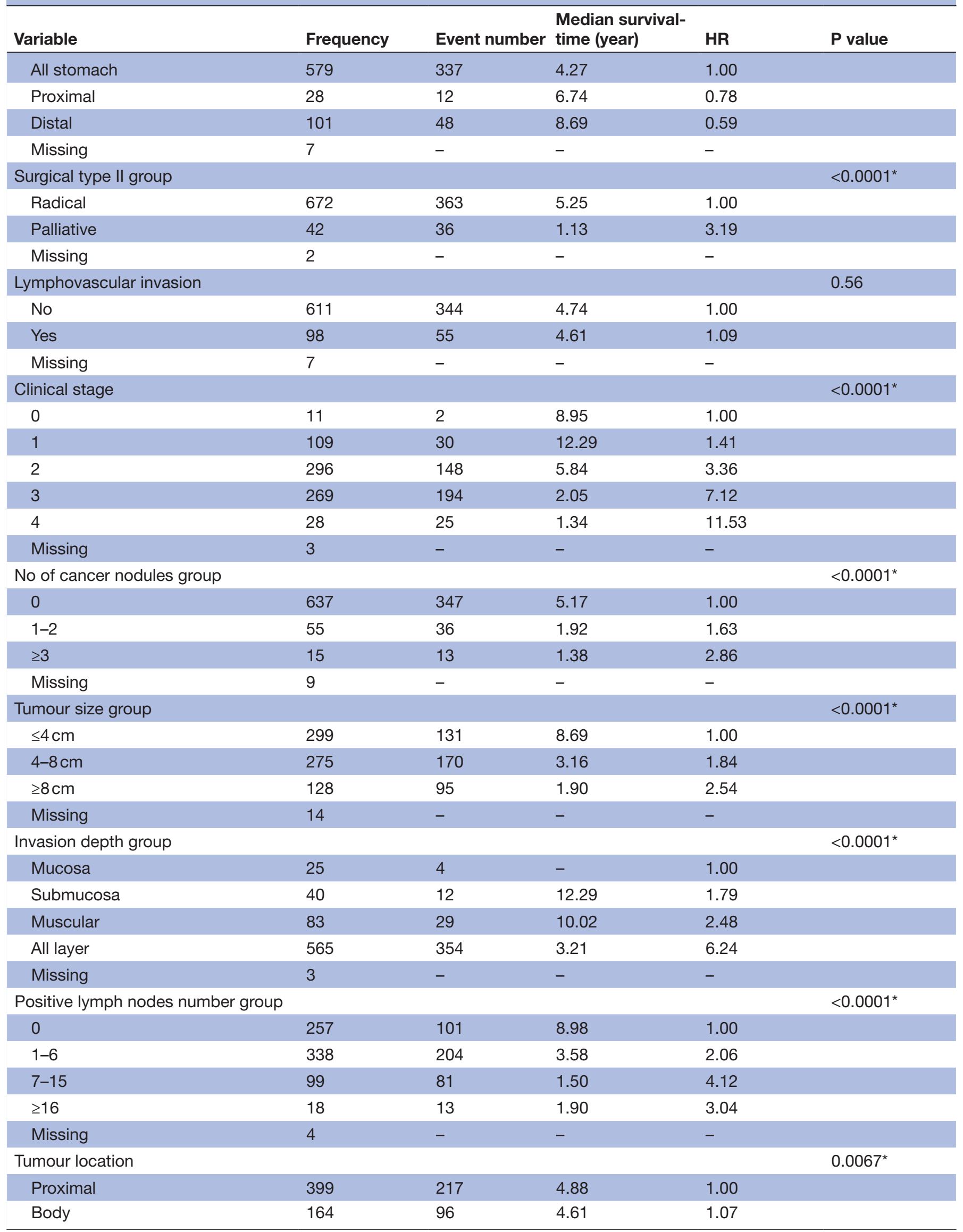

Continued 
Table 1 Continued

\begin{tabular}{|c|c|c|c|c|c|}
\hline Variable & Frequency & Event number & $\begin{array}{l}\text { Median survival- } \\
\text { time (year) }\end{array}$ & HR & $P$ value \\
\hline Distal & 99 & 48 & 6.14 & 0.91 & \\
\hline Missing & 3 & - & - & - & \\
\hline No of retrieved lymph nodes group & & & & & 0.10 \\
\hline $1-6$ & 196 & 103 & 6.10 & 1.77 & \\
\hline $7-15$ & 391 & 221 & 4.27 & 2.13 & \\
\hline$\geq 16$ & 116 & 72 & 3.17 & 2.48 & \\
\hline Missing & 7 & - & - & - & \\
\hline Age (missing $=1$ ) & 715 & & & 1.01 & 0.144 \\
\hline $\begin{array}{l}\text { No of retrieved lymph nodes } \\
\text { (missing=7) }\end{array}$ & 709 & & & 1.02 & $0.014^{*}$ \\
\hline $\begin{array}{l}\text { Lymph node metastasis rate } \\
(\text { missing }=5)\end{array}$ & 711 & & & 1.04 & 0.232 \\
\hline No of cancer nodules (missing=9) & 707 & & & 1.18 & $<0.0001^{*}$ \\
\hline
\end{tabular}

${ }^{*} \mathrm{p}$-value $<0.05$.

on the proximal of the stomach for 399 patients, on the body of the stomach for 164 patients, on the distal of the stomach for 99 , and 52 participants had more than two sites gastric lesions. Moreover, 672 patients proceeded to radical resection, and 42 proceed to palliative resection. Five hundred and sixty-five patients had all layer invasion of their stomachs. In addition, 579, 28 and 101 patients received all stomach, proximal and distal gastric surgery, respectively. The numbers of participants whose lymph node metastasis rate were 0 , between 0 and 0.35 , between 0.35 and 0.74 and $>0.74$ were $257,200,159$ and 95 , respectively. Furthermore, in this study, there were 299, 275 and 128 patients whose tumour sizes were smaller than $4 \mathrm{~cm}$, between 4 and $8 \mathrm{~cm}$, and larger than $8 \mathrm{~cm}$, respectively.

Sixteen significant prognostic factors of gastric cancer including Borrmann's type, surgical margin, $\mathrm{M}$ stage, $\mathrm{N}$ stage, T stage, lymph node metastasis rate group, surgical type II group, clinical stage, number of cancer nodules group, tumour size group, invasion depth group, positive lymph nodes number group, tumour location, positive lymph nodes number, number of retrieved lymph nodes and number of cancer nodules were identified $(\mathrm{p}<0.05)$ from the unadjusted analyses. However, there were no significant associations between survival time and gender, Lauren's classification, surgical type I group, lymphovascular invasion, number of retrieved lymph nodes group, age, age square and lymph node metastasis rate from the unadjusted analysis according to their large $\mathrm{p}$ values $(>0.05)$.

\section{Results from the adjusted analysis}

The results of the estimated HRs and their 95\% CI from the adjusted analysis were reported in table 2. The adjusted analysis identified seven variables and an interation that were associated with survival time. These variables and their estimated adjusted HR after adjusting for the other effects in the model were: age ( $\mathrm{HR}=0.888$, $\mathrm{p}$ value $=0.0016,95 \% \mathrm{CI} 0.825$ to 0.956 ), age square $(\mathrm{HR}=1.001, \mathrm{p}$ value $=0.0005,95 \%$ CI 1.000 to 1.002$)$, number of cancer nodules $(\mathrm{HR}=1.108$, $\mathrm{p}$ value $=0.0106$, 95\% CI 1.024 to 1.199 ), lymph node metastasis rate group (HR for $\leq 0.35,0.35-0.74, \geq 0.74: 1.033,1.780$ and 2.491, respectively; $p$ value $<0.0001,95 \%$ CI 0.768 to $1.390,1.320$ to $2.401,1.774$ to 3.497 , respectively), invasion depth group (HR for muscosa, muscular and all layer: 0.415, 1.291 and 2.095 respectively, $p$ value $<0.0001,95 \%$ CI 0.091 to $1.898,0.625$ to 2.669 and 1.089 to 4.032 , respectively), surgical type II group ( $\mathrm{p}$ value $<0.0001$ ), tumour size group ( $p$ value $=0.0010)$ and the interaction between surgical type II and tumour size.

\section{DISCUSSION}

In this study with total 716 gastric cancer patients, we identified the following clinicopathological factors which were independently associated with gastric carcinoma from the adjusted analysis: age (and age square), number of cancer nodules, lymph node metastasis rate, tumour size, type II surgery, invasion depth group and interaction 
Table 2 Results from adjusted analysis of prognostic variables

\begin{tabular}{|c|c|c|c|c|c|}
\hline Variables & $\begin{array}{l}\text { Estimated } \\
\text { coefficient }\end{array}$ & $\begin{array}{l}\text { Estimated } \\
\text { SE }\end{array}$ & $\begin{array}{l}\text { Estimated } \\
\text { HR }\end{array}$ & $95 \% \mathrm{Cl}$ of $\mathrm{HR}$ & $P$ value \\
\hline Age & -0.119 & 0.038 & 0.888 & 0.825 to 0.956 & $0.0016^{*}$ \\
\hline Age square & 0.001 & 0.0003 & 1.001 & 1.000 to 1.002 & $0.0005^{\star}$ \\
\hline No of cancer nodules & 0.103 & 0.040 & 1.108 & 1.024 to 1.199 & $0.0106^{*}$ \\
\hline Lymph node metastasis rate group & & & & & $<0.0001^{*}$ \\
\hline 0 (reference) & - & - & 1.000 & - & \\
\hline$\leq 0.35$ & -0.033 & 0.152 & 1.033 & 0.768 to 1.390 & \\
\hline $0.35-0.74$ & 0.577 & 0.153 & 1.780 & 1.320 to 2.401 & \\
\hline$\geq 0.74$ & 0.825 & 0.169 & 2.491 & 1.774 to 3.497 & \\
\hline Invasion depth group & & & & & $0.0041^{*}$ \\
\hline Submucosa & - & - & 1.000 & $(-$ to -$)$ & \\
\hline Mucosa & -0.880 & 0.776 & 0.415 & 0.091 to 1.898 & \\
\hline Muscular & 0.256 & 0.370 & 1.291 & 0.625 to 2.669 & \\
\hline All layer & 0.740 & 0.334 & 2.095 & 1.089 to 4.032 & \\
\hline $\begin{array}{l}\text { Surgical type } \\
\text { II group }\end{array}$ & & & & & $<0.0001^{*}$ \\
\hline Radical & - & - & & & \\
\hline Palliative & 1.757 & 0.364 & & & \\
\hline Tumour size & & & & & $0.0010^{*}$ \\
\hline$\leq 4 \mathrm{~cm}$ (reference) & - & - & & & \\
\hline $4-8 \mathrm{~cm}$ & 0.240 & 0.132 & & & \\
\hline$\geq 8 \mathrm{~cm}$ & 0.566 & 0.152 & & & \\
\hline $\begin{array}{l}\text { Surgical type } \\
\text { II group* tumour size }\end{array}$ & & & & & $0.0003^{*}$ \\
\hline Palliative versus radical $\leq 4 \mathrm{~cm}$ (reference) & - & - & & & \\
\hline Palliative $4-8 \mathrm{~cm}$ & -1.026 & 0.453 & & & \\
\hline Palliative $\geq 8 \mathrm{~cm}$ & -2.097 & 0.517 & & & \\
\hline
\end{tabular}

${ }^{*} \mathrm{p}$-value $<0.05$.

between surgical type II and tumour size. The adjusted analysis revealed that other variables, such as gender, Borrmann's type, TMN stage, tumour location, surgical type I group, surgical margin, lymphovascular invasion and number of retrieved lymph node, might not independently play a major role in the prognosis. For the variable 'age', we found that it had a non-linear effect on the outcome: both age and its square were significantly associated with survival time.

In our current study, among these identified risk factors, the prognosis of patients with gastric carcinoma was seen strongly affected by the rate of metastatic lymph nodes, which also has been emphasised in previous studies performed in different countries. ${ }^{24}{ }^{25}$ The result from the study by Kim et al indicated that the survival rate was remarkably decreased with metastatic lymph nodes rate increased. ${ }^{26}$ Msika et al also found that lymph node metastasis played an important role and was the only independent prognostic risk factor among 86 participants who underwent curative resection in their study. ${ }^{27}$
Furthermore, the German Gastric Carcinoma Study ${ }^{28}$ suggested that the lymph node metastasis rate should be considered as the significant independent prognostic variables among patients underwent resected gastric carcinoma, and indicated that extended lymph node dissection was the most critical treatment among patients with radical gastrectomy for long-term survival. Of the many factors relevant to survival time, depth of invasion also has been identified as one of the major prognostic factors from our current adjusted analysis. This finding is consistant with those from the literature..$^{29-32}$

Based on our adjusted analysis, age had a significant nonlinear effect on the survival time. We also found that tumour size and the number of cancer nodules were independent risk factors for prognostic. These two variables are recognised as tumour burden, which are related to poor prognosis susceptibility in another study as well. ${ }^{33}$ One Chinese cohort provided that a poorer prognosis in patients with gastric cancer whose number of cancer nodules were $>3 .{ }^{34}$ In addition, a Turkish study stated 
that cancer nodules are more observed in patients with the intestinal type and vascular invasive gastric cancers. ${ }^{35}$ On the other hand, tumour size is a valuable risk factor since it can be examined quite easily before the surgery, although the prognostic risk of tumour size among patients with gastric carcinoma maintains inconsistent. Some researches suggested that tumour size is not an independent prognostic variable in patients who had gastric carcinoma. ${ }^{36-38}$ However, other previous studies have displayed that tumour size should be considered as a risk feature for long-term survival after resection of gastric carcinoma, ${ }^{39-43}$ and there was a significant relationship between larger tumour size and lesion resectability. Tumour size of gastric cancer was a vital variable that affects the success of enbloc resection; patients with larger tumour sizes need higher level of expertise and experience for their treatment. Tumour size could raise with the depth of tumour invasion and the extent of lymph node metastasis increase: the size of the tumour is profoundly associated to 'Borrmann's type IV, adjacent organ invasion (T4) and higher lymph node and distant metastasis rate ${ }^{3744}$ A possible explaination is that most patients with stage III or stage IV cancers had a relatively lower radical resection and remained a lower 5-year survival rate. ${ }^{45}$

Our results also showed that patients who received palliative gastrectomy had poorer prognosis and higher risks compared with patients with radical gastrectomy. The results from Dutch clinical randomise trial ${ }^{46}$ suggested that palliative gastrectomy could be beneficial for younger patients (age $<70$ years) whose tumour load was restricted to one metastatic site. On the contrary, a previous study ${ }^{47}$ indicated that "palliative gastrectomy has no survival benefit ( $\mathrm{p}$-value $=0.705,0.331$, respectively) in the peritoneal dissemination and multi-organ metastases group'. Another study found that palliative gastrectomy showed no obvious favourable effect on long-term survival or improvement of the quality of life among patients with gastric cancer. ${ }^{48}$ Moreover, Kanhere et al suggested that radical gastrectomy remained the only curative treatment option for gastric cancer. ${ }^{49}$ The interaction between tumour size and surgical type II was found significant from our adjusted analysis. It showed that patients who had tumour size $\leq 4 \mathrm{~cm}$ and palliative gastrectomy had the lowest risk while the highest risk was found in patients who had tumour size $\leq 4 \mathrm{~cm}$ and palliative gastrectomy. On the contrary, patients who had larger tumour size $(\geq 8 \mathrm{~cm})$ with palliative gastrectomy have the second lowest prognosis risk.

There were several strengths and limitations in our current study. We used the Cox proportional hazard regression model, which is one of the most commonly used methods for adjusted analyses with survival time as the dependent variable. Our findings showed that tumour size, interacted with surgical type II, encompasses important prognostic information for gastric cancer. Based on Jun et $a l^{50}$ the tumour size was statistically significantly and independently associated with gastric carcinoma-related survival, and this risk factor was a vital predictor for advanced gastric cancer, although it may not be detectable in early gastric carcinoma. In addition, our study includes patients with a long-term follow-up duration, which was rarely seen from other studies conducted in China. However, all the patients in this study were recruited from Anhui, a province of China. This fact could lead to a lack of generalisability of our findings to the general Chinese population. Finally, the present study has limitations inherent to all observational studies. For instance, some potential confounders may not be recognised and included in the study and selection bias could exist due to loss to follow-up.

\section{CONCLUSION}

Currently, identifying and predicting important prognosis indicators before treatment are critical for gastric cancer patients. In our study, seven prognostic risk characteristics and one interaction have been identified in patients with gastric carcinoma. The findings from our study are useful and applicable for clinical decision-making. They also provide a benchmark for planning future prognosis and treatment for gastric cancer patients. Our findings can also be used to improve early detection and to investigate the feasibility and survival benefit of therapy for patients with gastric carcinoma.

Acknowledgements The authors would like to thank Drs Qiang Wu, Hao Li and Xianghong Chen from the Department of Pathology at the First Affiliated Hospital of Anhui Medical University for providing excellent technical support of this study. The authors are grateful to the reviewers for their helpful comments which result in an improved presentation of this report.

Contributors $\mathrm{KH}, \mathrm{ZC}$ and Q-FW designed and oversaw the study. SW, ZW, LL, $\mathrm{ZH}$ and WY contributed to data collection and analysis. KH, SW, ZW, ZC and Q-FW drafted the manuscript. All authors participated in the discussion and approved the final manuscript.

Funding This work was supported in part by the Hefei National Laboratory for Physical Sciences at Microscale. The funders played no role in the study design, data collection and analysis, decision to publish or preparation of the manuscript.

\section{Competing interests None declared.}

Patient consent for publication Not required.

Ethics approval This study was approved by the Institutional Review Board of the First Affiliated Hospital of Anhui Medical University in China (IRB approval number: PJ-2019-02-19).

Provenance and peer review Not commissioned; externally peer reviewed. Data availability statement No data are available.

Open access This is an open access article distributed in accordance with the Creative Commons Attribution Non Commercial (CC BY-NC 4.0) license, which permits others to distribute, remix, adapt, build upon this work non-commercially, and license their derivative works on different terms, provided the original work is properly cited, appropriate credit is given, any changes made indicated, and the use is non-commercial. See: http://creativecommons.org/licenses/by-nc/4.0/.

\section{REFERENCES}

1. WHO. International agency for research on cancer, 2018. Available: http://gco.iarc.fr/today/

2. Bray F, Ferlay J, Soerjomataram I, et al. Global cancer statistics 2018: GLOBOCAN estimates of incidence and mortality worldwide for 36 cancers in 185 countries. CA Cancer J Clin 2018;68:394-424. 
3. Kamangar F, Dores GM, Anderson WF. Patterns of cancer incidence, mortality, and prevalence across five continents: defining priorities to reduce cancer disparities in different geographic regions of the world. JCO 2006:24:2137-50.

4. Guggenheim DE, Shah MA. Gastric cancer epidemiology and risk factors. J Surg Oncol 2013;107:230-6.

5. Forman D, Burley VJ. Gastric cancer: global pattern of the disease and an overview of environmental risk factors. Best Pract Res Clin Gastroenterol 2006;20:633-49.

6. Chen W, Zheng R, Baade PD, et al. Cancer statistics in China, 2015. CA Cancer J Clin 2016;66:115-32.

7. Lindblad M, Rodríguez LAG, Lagergren J. Body mass, tobacco and alcohol and risk of esophageal, gastric cardia, and gastric non-cardia adenocarcinoma among men and women in a nested case-control study. Cancer Causes Control 2005;16:285-94.

8. Lagergren J, Bergström R, Lindgren A, et al. Symptomatic gastroesophageal reflux as a risk factor for esophageal adenocarcinoma. N Engl J Med 1999;340:825-31.

9. Strumylaite L, Zickute J, Dudzevicius J, et al. Salt-preserved foods and risk of gastric cancer. Medicina 2006;42:164-70.

10. Liang Y-X, Deng J-Y, Guo H-H, et al. Characteristics and prognosis of gastric cancer in patients aged $\geq 70$ years. World $J$ Gastroenterol 2013;19:6568-78.

11. Crew KD, Neugut Al. Epidemiology of gastric cancer. World $J$ Gastroenterol 2006;12:354-62.

12. Karimi P, Islami F, Anandasabapathy S, et al. Gastric cancer: descriptive epidemiology, risk factors, screening, and prevention. Cancer Epidemiology Biomarkers \& Prevention 2014;23:700-13.

13. Howlader NJhscgc. Seer cancer statistics review, 1975-2008, 2011.

14. Bray F, Ferlay J, Soerjomataram I, et al. GLOBOCAN estimates of incidence and mortality worldwide for 36 cancers in 185 countries. CA Cancer J Clin 2018;2018.

15. Magalhães H, Fontes-Sousa M, Machado M. Immunotherapy in advanced gastric cancer: an overview of the emerging strategies. Canadian Journal of Gastroenterology and Hepatology 2018;2018:1-8.

16. Ajani JA. Is the addition of cisplatin to $\mathrm{S}-1$ better than $\mathrm{S}-1$ alone for patients with advanced gastroesophageal cancer? Nat Clin Pract Oncol 2008;5:508-9.

17. Penson DF. Re: variation in surgical-readmission rates and quality of hospital care. J Urol 2014;191:1363-4.

18. Lee K-G, Lee H-J, Yang J-Y, et al. Risk factors associated with complication following gastrectomy for gastric cancer: retrospective analysis of prospectively collected data based on the Clavien-Dindo system. J Gastrointest Surg 2014;18:1269-77.

19. Paulino Filho A, Paulino F, LC de. [Preoperative and postoperative care of patients with gastric cancer]. Hospital 1961;59:201-9.

20. Qiu M-zhen, Cai M-yan, Zhang D-sheng, et al. Clinicopathological characteristics and prognostic analysis of Lauren classification in gastric adenocarcinoma in China. $J$ Trans/ Med 2013;11:58.

21. Vauhkonen M, Vauhkonen $\mathrm{H}$, Sipponen P. Pathology and molecular biology of gastric cancer. Best Pract Res Clin Gastroenterol 2006;20:651-74.

22. Smith DD, Schwarz RR, Schwarz RE. Impact of total lymph node count on staging and survival after gastrectomy for gastric cancer: data from a large US-population database. JCO 2005;23:7114-24.

23. Edge SB, AJCo C. AJCC cancer staging handbook: from the AJCC cancer staging manual. Springer New York, 2010.

24. Lee WJ, Lee PH, Yue SC, et al. Lymph node metastases in gastric cancer: significance of positive number. Oncology 1995;52:45-50.

25. Yokota T, Ishiyama S, Saito T, et al. Lymph node metastasis as a significant prognostic factor in gastric cancer: a multiple logistic regression analysis. Scand J Gastroenterol 2004;39:380-4.

26. Kim J-P, Lee J-H, Kim S-J, et al. Clinicopathologic characteristics and prognostic factors in 10783 patients with gastric cancer. Gastric Cancer 1998;1:125-33.

27. Msika S, Benhamiche AM, Jouve JL, et al. Prognostic factors after curative resection for gastric cancer. A population-based study. Eur $J$ Cancer 2000;36:390-6.
28. Roder JD, Böttcher K, Siewert JR, et al. Prognostic factors in gastric carcinoma. Results of the German Gastric Carcinoma Study 1992 1993;72:2089-97.

29. Shimizu H, Ichikawa D, Komatsu S, et al. The decision criterion of histological mixed type in "T1/T2" gastric carcinoma--comparison between TNM classification and Japanese Classification of Gastric Cancer. J Surg Oncol 2012;105:800-4.

30. Ikeda $\mathrm{M}$, Furukawa $\mathrm{H}$, Imamura $\mathrm{H}$, et al. Poor prognosis associated with thrombocytosis in patients with gastric cancer. Ann Surg Oncol 2002;9:287-91.

31. Han SL, Tang HJ, Hua YW, et al. Expression of COX-2 in stomach cancers and its relation to their biological features. Dig Surg 2003;20:107-14.

32. Joo Y-E, Oh W-T, Rew J-S, et al. Cyclooxygenase-2 expression is associated with well-differentiated and intestinal-type pathways in gastric carcinogenesis. Digestion 2002;66:222-9.

33. Chu DZ, Lang NP, Thompson C, et al. Peritoneal carcinomatosis in nongynecologic malignancy. A prospective study of prognostic factors. Cancer 1989;63:364-7.

34. Quanwen L, Zhengfang Z, Jianxin C. The value of cancer nodules in staging and prognosis evaluation of gastric cancer patients. Chinese Journal of Gastrointestinal Surgery 2017;20:277-82.

35. Ersen A, Unlu MS, Akman T, et al. Tumor deposits in gastric carcinomas. Pathol Res Pract 2014;210:565-70.

36. Michelassi F, Takanishi DM, Pantalone D, et al. Analysis of clinicopathologic prognostic features in patients with gastric adenocarcinoma. Surgery 1994;116:804-9.

37. Yokota T, Ishiyama S, Saito T, et al. Is tumor size a prognostic indicator for gastric carcinoma? Anticancer Res 2002;22:3673-7.

38. Yu CC, Levison DA, Dunn JA, et al. Pathological prognostic factors in the second British stomach cancer Group trial of adjuvant therapy in resectable gastric cancer. Br J Cancer 1995;71:1106-10.

39. Isomoto H, Shikuwa S, Yamaguchi N, et al. Endoscopic submucosal dissection for early gastric cancer: a large-scale feasibility study. Gut 2009;58:331-6.

40. Oda I, Gotoda T, Hamanaka H, et al. Endoscopic submucosal dissection for early gastric cancer: technical feasibility. operation time and complications from a large consecutive series 2005;17:54-8.

41. Dassen A, Lemmens V, Van De Poll-franse L, et al. Trends in incidence. treatment and survival of gastric adenocarcinoma between 1990 and 2007: a population-based study in the Netherlands 2010;46:1101-10.

42. Adachi $\mathrm{Y}$, Oshiro $\mathrm{T}$, Mori $\mathrm{M}$, et al. Tumor size as a simple prognostic indicator for gastric carcinoma. Ann Surg Oncol 1997;4:137-40.

43. Giuliani A, Caporale A, Di Bari M, et al. Maximum gastric cancer diameter as a prognostic indicator: univariate and multivariate analysis 2003;22:531-8.

44. Shiraishi N, Sato K, Yasuda K, et al. Multivariate prognostic study on large gastric cancer. J Surg Oncol 2007;96:14-18.

45. Yasuda K, Shiraishi N, Adachi Y, et al. Risk factors for complications following resection of large gastric cancer. Br J Surg 2001;88:873-7.

46. Hartgrink $\mathrm{HH}$, Putter $\mathrm{H}$, Klein Kranenbarg $\mathrm{E}$, et al. Dutch gastric cancer G. value of palliative resection in gastric cancer. Br J Surg 2002;89:1438-43.

47. Chen S, Li Y-F, Feng X-Y, et al. Significance of palliative gastrectomy for late-stage gastric cancer patients. J Surg Oncol 2012;106:862-71.

48. Ouchi K, Sugawara T, Ono H, et al. Therapeutic significance of palliative operations for gastric cancer for survival and quality of life. J Surg Oncol 1998;69:41-4.

49. Kanhere H, Goel R, Finlay B, et al. Radical gastrectomy: still the cornerstone of curative treatment for gastric cancer in the perioperative chemotherapy Era-A single Institute experience over a decade. Int J Surg Oncol 2018;2018:1-6.

50. Jun $\mathrm{KH}$, Jung $\mathrm{H}$, Baek JM, et al. Does tumor size have an impact on gastric cancer? a single Institute experience. Langenbecks Arch Surg 2009;394:631-5. 